\title{
Evaluation of relationship between bone mineral density and fragility fracture in perimenopausal women between 40-58 years of age: a hospital based prospective observational study
}

\author{
Arvind Kumar ${ }^{1}$, Mozammil Pheroz ${ }^{1}$, Rajesh K. Chopra ${ }^{1}$, Benthungo Tungoe ${ }^{1}$, \\ Narendra Kumar', Yatish Aggarwal ${ }^{2}$, Samrin Sarwar ${ }^{3}$, Manoj Soni ${ }^{4}$
}

\author{
${ }^{1}$ Department of Orthopaedics, CIO, ${ }^{2}$ Department of Radiodiagnossis, ${ }^{3}$ Department of Ophthalmology, Safdarjung \\ Hospital, New Delhi, Delhi, India \\ ${ }^{4}$ Department of Orthopaedics, Velmed Hospital, Turner Road, Clement Town, Dehradun, Uttarakhand, India
}

Received: 03 May 2019

Revised: 17 May 2019

Accepted: 18 May 2019

\section{*Correspondence:}

Dr. Mozammil Pheroz,

E-mail: muzammilphrz@ rediffmail.com

Copyright: ( $)$ the author(s), publisher and licensee Medip Academy. This is an open-access article distributed under the terms of the Creative Commons Attribution Non-Commercial License, which permits unrestricted non-commercial use, distribution, and reproduction in any medium, provided the original work is properly cited.

\begin{abstract}
Background: At present the risk assessment for osteoporosis using low bone mineral density (BMD) is based on data obtained from elderly females, largely $\geq 65$ years of age. The risk factors for low peak bone mass or accelerated bone loss that occurs during perimenopausal phase is ignored in this risk assessment. Osteoporosis is found to occur at a relatively younger age in the Indian population. Although lower BMD values have an established identity as a major risk factor for fractures in postmenopausal women, we endeavour to evaluate relationship between bone mineral density and fragility fracture in perimenopausal women.

Methods: 65 Patients were recruited for the study. After X-ray of involved part, patients were divided into cases (with fracture, $n=33$ ) and control (no bony injury, $n=32$ ). All patients underwent dual energy X-ray absorptiometry (DEXA) scan. Results of DEXA scans were evaluated in both the groups. BMD was expressed in $\mathrm{g} / \mathrm{cm}^{2}$.

Results: 33 patients $(50.77 \%)$ were diagnosed as fracture, 32(49.23\%) had no bony injury. Threshold bone mineral density (BMD) for fragility fracture found out asfor L1, cut off $\leq 0.767$. For L2, cut off $\leq 0.829$. For L3, cut off $\leq 0.811$. L4, cut off $\leq 0.798$. For L1-L4, cut off $\leq 0.845$. For left femur total hip, cut off $\leq 0.918$. For left forearm-total, cut off $\leq 0.411$. For right femur total hip-cut off $\leq 0.795$. For right forearm-total, cut-off $\leq 0.382$.

Conclusions: Perimenopausal women having BMD below threshold for involved site are at risk of fragility fracture and should be given prophylactic treatment to improve bone mineral density.
\end{abstract}

Keywords: Bone mineral density, Osteoporosis, Perimenopausal female

\section{INTRODUCTION}

Osteoporosis is most common skeletal disorder in the elderly, being characterized by impaired bone mass and microarchitecture, bone strength and consequently, increase risk of fracture. ${ }^{1}$ Many clinical guidelines recommend risk factor assessment and measurement of bone mineral density (BMD) through dual energy X-ray absorptiometry (DEXA) to identify individuals at high risk of fracture., ${ }^{2,3}$ Risk factors have been extensively characterized in women over the age of 65 years and are used in practice, to predict fractures.

A low bone mineral density in osteoporosis patients poses increased risk of sustaining fractures, sometimes even with low energy trauma. Early diagnosis and treatment of osteoporosis can reduce fracture cases due to trivial trauma. Therefore, there is a need for identification of 
those patients who are at risk of sustaining a fracture and would benefit most from the available therapy. Providing treatment to the appropriate risk group would reduce the number of fractures, as well as the adverse effects associated with duration of treatment.

Current risk assessment for low BMD is based primarily on data from older women, largely $\geq 65$ years of age which does not directly incorporate risk factors for low peak bone mass or accelerated pre-menopausal bone loss. ${ }^{6}$ Risk factors identified in older women may not be relevant to, or highly prevalent among, younger women. Appropriate BMD testing among younger women first requires the identification of risk factors for low BMD in this population. Although the absolute risk of fragility fracture is low in younger women, detection of individuals with significantly reduced BMD will assist with implementation of preventive measures and closer surveillance of those who may benefit from early intervention.

Premenopausal women with low bone mineral density (BMD) are increasingly being identified. ${ }^{7}$ Vast quantity of literatures could be found that support the lower BMD values as a major risk factor in postmenopausal women but little is known regarding clinical significance of lower BMD before menopause is established in females. Low hip BMD has been shown to predict hip fracture in postmenopausal and perimenopausal women, Fractures are caused by forces that exceed bone strength, and can occur at any age..$^{8-11}$ Bone strength is determined by bone geometry, microarchitecture, and material properties such as BMD.

Henceforth, this study deals with evaluation of relationship between bone mineral density and fragility fracture in Indian perimenopausal women aged above 40 years.

\section{METHODS}

This is a prospective study, done at Central Institute of Orthopaedics, VMMC \& Safdarjung Hospital, New Delhi. Period of study was from October 2014 to April 2016 including 65 cases. Female patients presenting to the outpatients department of C.I.O., V.M.M.C \& Safdarjung Hospital with complain of pain due to trivial trauma were assessed. After clinical and radiological examination, patients were recruited for the study if they fulfill the inclusion criteria.

\section{Inclusion criteria}

Inclusion criteria were women aged above 40 years with complain of pain due to trivial trauma. ${ }^{12}$

\section{Exclusion criteria}

Exclusion criteria were not consenting, age less than 40 , any high velocity trauma like road traffic accident, patients on steroids, heparin, warfarin, lithium, anti retroviral therapy, patients with history of renal, diabetic, metabolic bone disease, alcoholism, smoking. Paraplegic and pregnant women also excluded from the study.

Patients involved in the study were divided into case and control group, depending upon presence and absence of fracture. All patients having fractures were kept as cases $(n=33)$ and those without having any fractures were designated as controls $(n=32)$.

\section{Procedure}

Patients attending the outpatient department of Safdarjung Hospital coming with chief complaints of pain due to trivial trauma, underwent thorough examination after taking informed consent and explaining the nature of study. After clinical examination patients were subjected to laboratory and radiological investigations. Laboratory investigations includedcomplete haemogram with erythrocyte sedimentation rate, serum electrolyte, renal function test, liver function test and, random blood sugar. Radiological examination comprised of X-rays of both hip with pelvis anteroposterior view. Both anteroposterior and lateral views were taken for lumbosacral spine and wrist of involved side. DEXA scan was done for right forearm, left forearm, right hip, left hip and, spine from lumbar $1^{\text {st }}$ to lumbar $4^{\text {th }}$ vertebrae (L1-L4).

The data collected in terms of values of bone mineral density, compared and evaluated in both groups of females.

\section{Statistical analysis}

Categorical variables were presented in number and percentage (\%) and continuous variables were presented as mean \pm SD and median. Normality of data was tested by Kolmogorov-Smirnov test. If the normality was rejected then non parametric test was used. Quantitative variables were compared using un-paired T-test/Mann-Whitney Test (when the data sets were not normally distributed) between the two groups. Qualitative variables were correlated using Chi-Square test /Fisher's exact test. Receiver operating characteristic curve was used to find out the cutoff point, sensitivity, specificity of BMD for predicting fracture. A $\mathrm{p}<0.05$ was considered statistically significant. The data was entered in MS EXCEL spreadsheet and analysis was done using Statistical Package for Social Sciences (SPSS) version 21.0.

\section{RESULTS}

\section{Demographic characteristics of the study population}

In this study, out of the total 65 female patients that participated in the study, 38 patients $(58.46 \%)$ were in (41-45 years) age group, 23 patients $(35.38 \%)$ were in (46-50 years) and 4 patients $(6.15 \%)$ fell in (>50 years) 
age group (Table 1). The mean age was 45.72 year with $\mathrm{SD} \pm 4.83$, median was 45 years. Minimum and maximum age was 41 year and 66 years. Inter quartile range was 42-47.250.

Table 1: Age distribution among the study population $(n=65)$.

\begin{tabular}{|c|c|c|c|c|}
\hline & & Fracture & & \\
\hline & & No bony injury (\%) & Yes $(\%)$ & Total $(\%)$ \\
\hline & 1) $41-45$ & 50.00 & 50.00 & 100.00 \\
\hline Age distribution & 2) $46-50$ & 52.17 & 47.83 & 100.00 \\
\hline & 3) $>50$ & 25.00 & 75.00 & 100.00 \\
\hline Total & & 49.23 & 50.77 & 100.00 \\
\hline
\end{tabular}

Table 2: BMD values in the study population and its statistical interpretation.

\begin{tabular}{|llllllll|}
\hline & $\begin{array}{l}\text { Area under } \\
\text { the ROC } \\
\text { curve (AUC) }\end{array}$ & $\begin{array}{l}\text { Standard } \\
\text { error }\end{array}$ & $\begin{array}{l}\text { 95\% Confidence } \\
\text { interval }\end{array}$ & $\begin{array}{l}\text { Significance } \\
\text { level p } \\
\text { (Area=0.5) }\end{array}$ & $\begin{array}{l}\text { Cut off } \\
\text { point }\end{array}$ & $\begin{array}{l}\text { Sensitivity } \\
\text { Specificity }\end{array}$ \\
\hline BMD L1 & 0.883523 & 0.0463 & 0.779835 to 0.949789 & $<0.0001$ & $\leq 0.767$ & 81.82 & 90.62 \\
\hline BMD L2 & 0.870265 & 0.0531 & 0.763788 to 0.940771 & $<0.0001$ & $\leq 0.829$ & 87.88 & 90.62 \\
\hline BMD L3 & 0.832860 & 0.0549 & 0.719758 to 0.913927 & $<0.0001$ & $\leq 0.811$ & 78.79 & 87.5 \\
\hline BMD L4 & 0.864583 & 0.0511 & 0.756988 to 0.936818 & $<0.0001$ & $\leq 0.798$ & 75.76 & 93.75 \\
\hline $\begin{array}{l}\text { BMD left } \\
\text { femur-total hip }\end{array}$ & 0.872159 & 0.0524 & 0.766065 to 0.942077 & $<0.0001$ & $\leq 0.918$ & 84.85 & 87.5 \\
\hline $\begin{array}{l}\text { BMD left } \\
\text { forearm-total }\end{array}$ & 0.77178 & 0.0637 & 0.650910 to 0.866748 & $<0.0001$ & $\leq 0.411$ & 84.85 & 75 \\
\hline $\begin{array}{l}\text { BMD right } \\
\text { femur-total hip }\end{array}$ & 0.857008 & 0.0519 & 0.747988 to 0.931474 & $<0.0001$ & $\leq 0.795$ & 78.79 & 90.62 \\
\hline $\begin{array}{l}\text { BMD right } \\
\text { forearm-total }\end{array}$ & 0.963542 & 0.0289 & 0.884845 to 0.994305 & $<0.0001$ & $\leq 0.382$ & 93.94 & 96.87 \\
\hline $\begin{array}{l}\text { BMD spine- } \\
\text { L1-L4 }\end{array}$ & 0.857008 & 0.0524 & 0.747988 to 0.931474 & $<0.0001$ & $\leq 0.845$ & 84.85 & 87.5 \\
\hline
\end{tabular}

\section{Bone mineral density recorded in the study population}

For right forearm mean of total BMD was $0.43 \mathrm{~g} / \mathrm{cm}^{2}$ with $\mathrm{SD} \pm 0.18$. For left forearm total, mean BMD was $0.48 \mathrm{~g} / \mathrm{cm}^{2}$ with $\mathrm{SD} \pm 0.22$. For right femur total hip, mean BMD was $0.87 \mathrm{~g} / \mathrm{cm}^{2}$ with $\mathrm{SD} \pm 0.14$. For left femur total hip, mean BMD was $0.88 \mathrm{~g} / \mathrm{cm}^{2}$ with $\mathrm{SD} \pm 0.17$. For spine $\mathrm{L} 1-\mathrm{L} 4$, mean $\mathrm{BMD}$ was $0.82 \mathrm{~g} / \mathrm{cm}^{2}$ with $\mathrm{SD} \pm 0.15$. For spine $\mathrm{L} 1$, mean BMD was $0.78 \mathrm{~g} / \mathrm{cm}^{2}$ with $\mathrm{SD} \pm 0.15$. For spine L2, mean BMD was $0.8 \mathrm{~g} / \mathrm{cm}^{2}$ with $\mathrm{SD} \pm 0.15$. For spine $\mathrm{L} 3$, mean BMD was $0.81 \mathrm{~g} / \mathrm{cm}^{2}$ with $\mathrm{SD} \pm 0.16$. For spine $\mathrm{L} 4$, mean $\mathrm{BMD}$ was $0.86 \mathrm{~g} / \mathrm{cm}^{2}$ with $\mathrm{SD} \pm 0.18$.

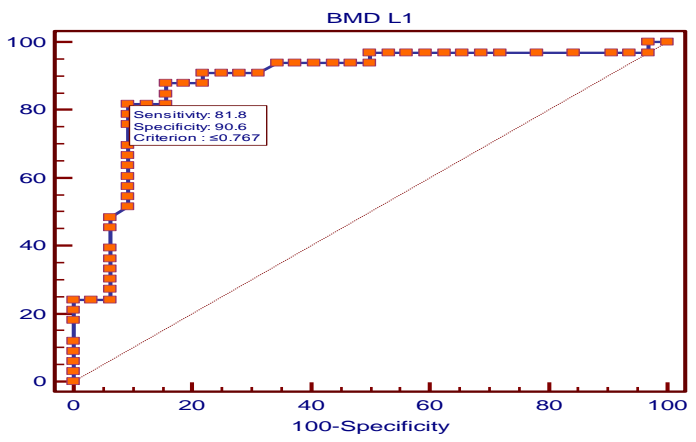

Figure 1: ROC curve of BMD of lumbar first (L1) vertebra.
When reciever operating characteristic (ROC) curve was plotted (Table 2), it was found that for BMD of L1, Area under the ROC curve (AUC) was 0.883523 with standard error $0.0463 .95 \%$, confidence interval of 0.779835 to 0.949789 with significance level $\mathrm{p}<0.0001$ (Area=0.5) and cut off point $\leq 0.767$ having sensitivity 81.82 and specificity 90.62 (Figure 1).

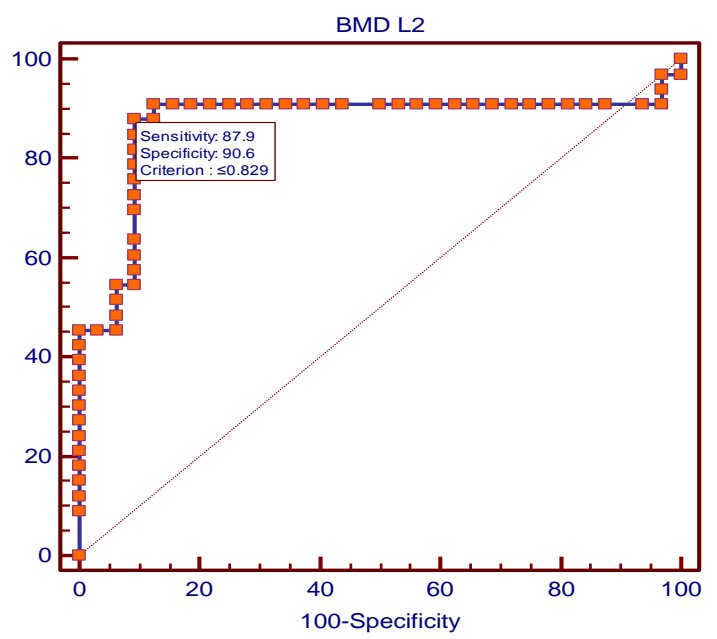

Figure 2: ROC curve of BMD of lumbar second (L2) vertebra. 
For BMD L2, Area under the ROC curve (AUC) was 0.870265 with standard error was $0.0531 .95 \%$, confidence interval was 0.763788 to 0.940771 with significance level $\mathrm{p}<0.0001 \quad($ Area $=0.5$ ) cut off point $\leq 0.829$ having sensitivity 87.88 and specificity 90.62 (Figure 2).

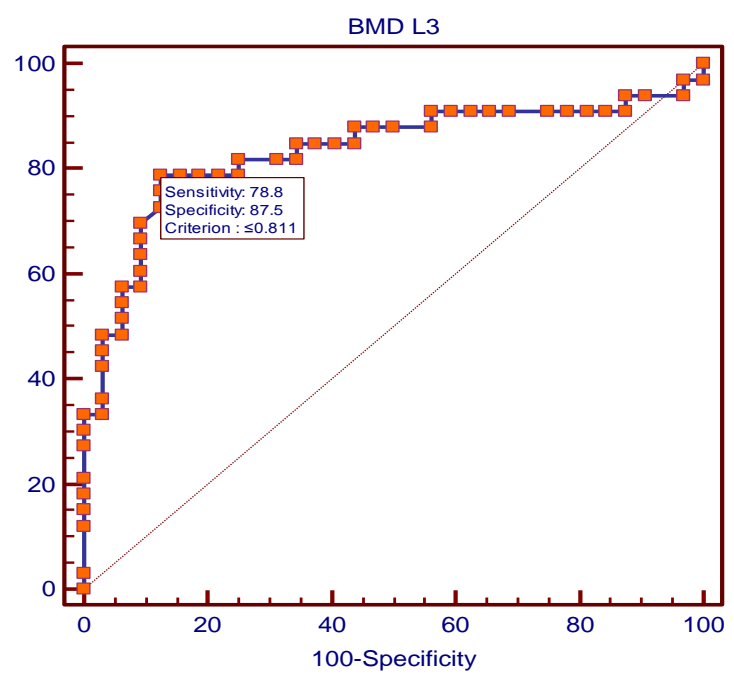

Figure 3: ROC curve of BMD of lumbar third (L3) vertebra.

For BMD L3, area under the ROC curve (AUC) was 0.832860 with standard error of $0.0549 .95 \%$ confidence interval of 0.719758 to 0.913927 with significance level $\mathrm{p}<0.0001$ (Area=0.5), cut off point $\leq 0.811$ having sensitivity 78.79 and specificity 87.5 (Figure 3 ).

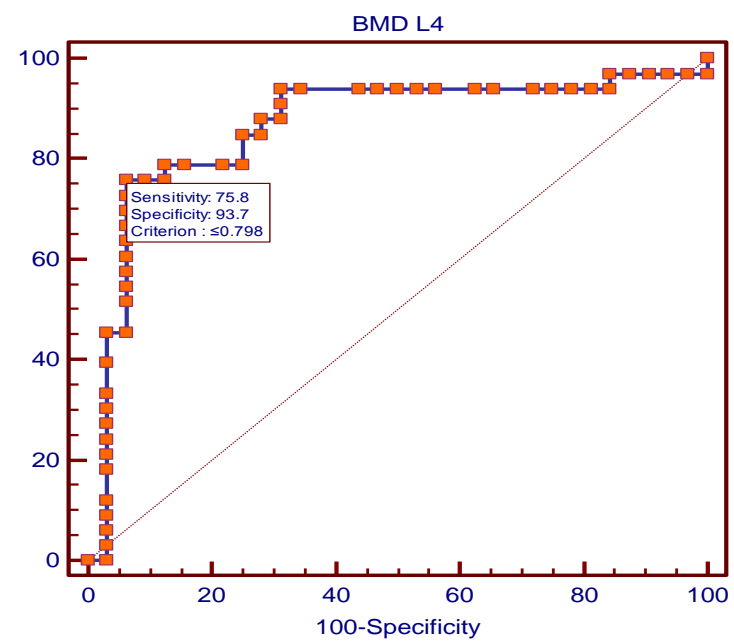

Figure 4: ROC curve of BMD of lumbar fourth (L4) vertebra.

For BMD L4, area under the ROC curve (AUC) was 0.864583 with standard error of $0.0511 .95 \%$, confidence interval 0.756988 to 0.936818 with significance level $\mathrm{p}<0.0001$ (Area=0.5), cut off point $\leq 0.798$ having sensitivity 75.76 and specificity 93.75 (Figure 4).

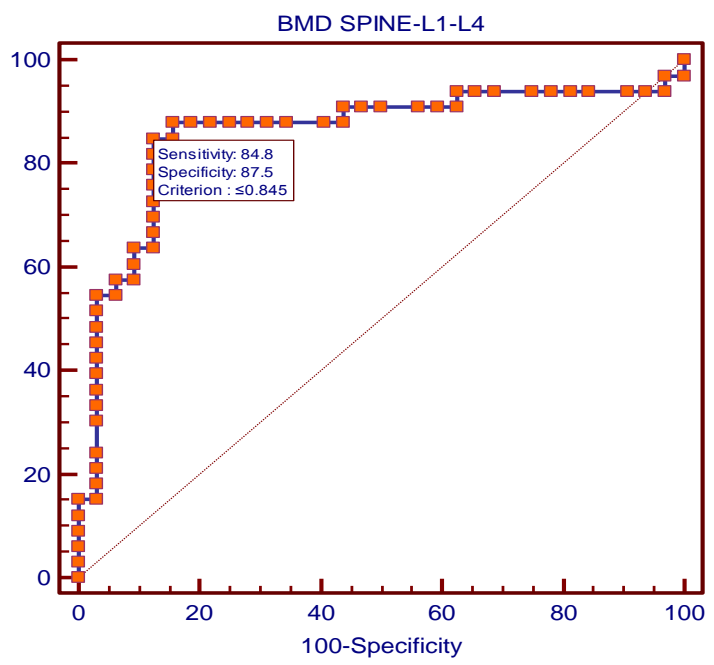

Figure 5: ROC curve of BMD of lumbar vertebrae 1-4 (L1-L4).

For BMD L1-L4, area under the ROC curve (AUC) 0.857008 with standard error of $0.0524 .95 \%$ confidence interval 0.747988 to 0.931474 with significance level $\mathrm{p}<0.0001$ (Area=0.5), cut off point $\leq 0.845$ having sensitivity of 84.85 and specificity of 87.5 (Figure 5).

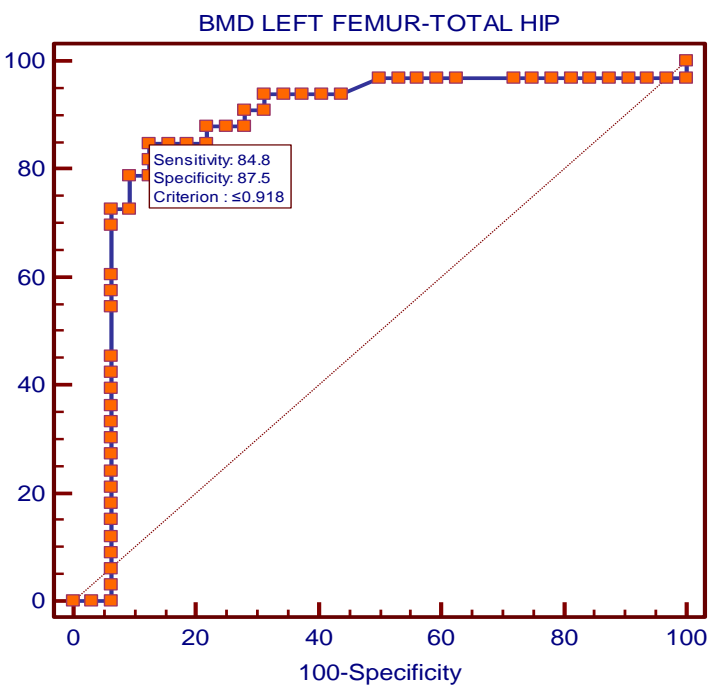

Figure 6: ROC curve of BMD of left femur- total hip.

For BMD Left femur total hip, area under the ROC curve (AUC) was 0.872159 with standard error of $0.0524 .95 \%$, confidence interval 0.766065 to 0.942077 with significance level $\mathrm{p}<0.0001$ (Area $=0.5$ ), cut off point $\leq 0.918$ having sensitivity 84.85 and specificity 87.5 (Figure 6).

For BMD Left forearm-total, area under the ROC curve (AUC) was 0.77178 with standard error $=0.0637 .95 \%$, confidence interval 0.650910 to 0.866748 with significance level $\mathrm{p}<0.0001$ (Area $=0.5$ ), cut off point $\leq 0.411$ having sensitivity 84.85 and specificity 75 (Figure $7)$. 


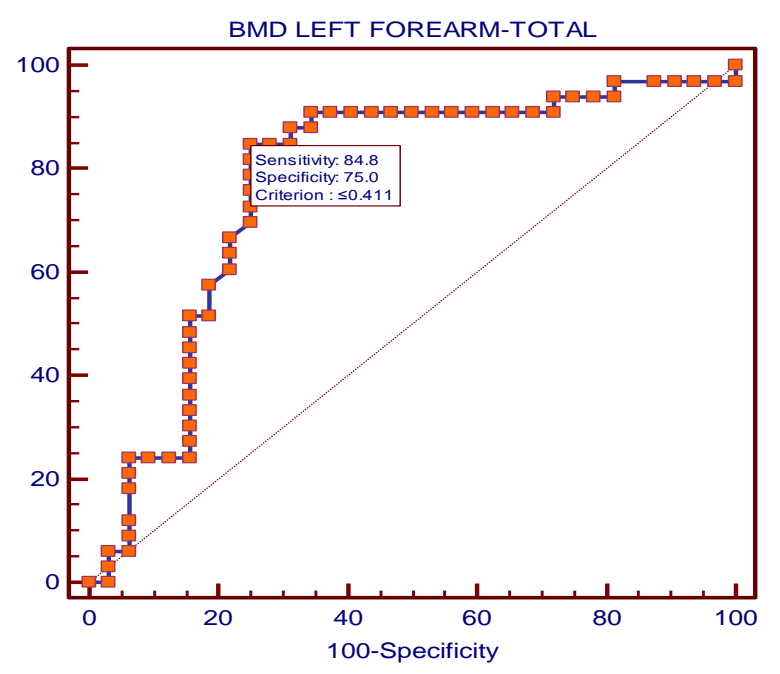

Figure 7: ROC curve of BMD of left forearm total.

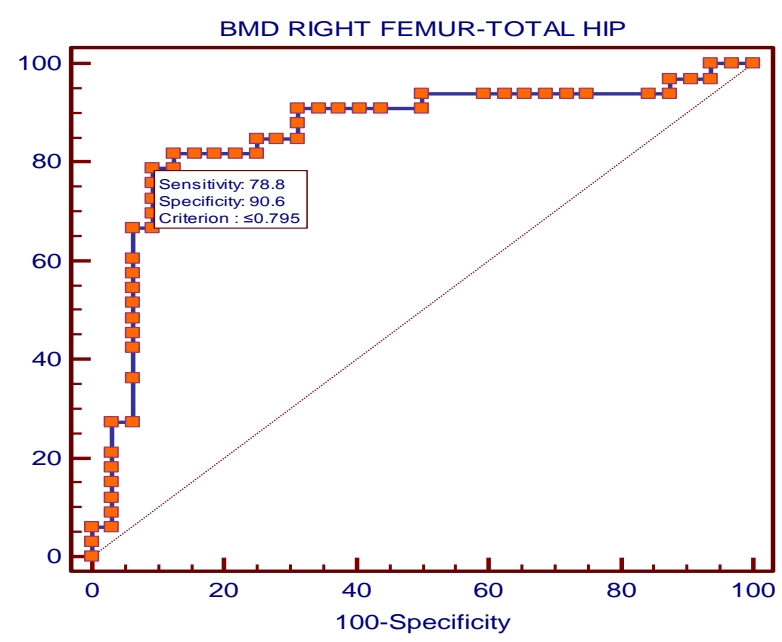

Figure 8: ROC curve of BMD of right femur -total hip.

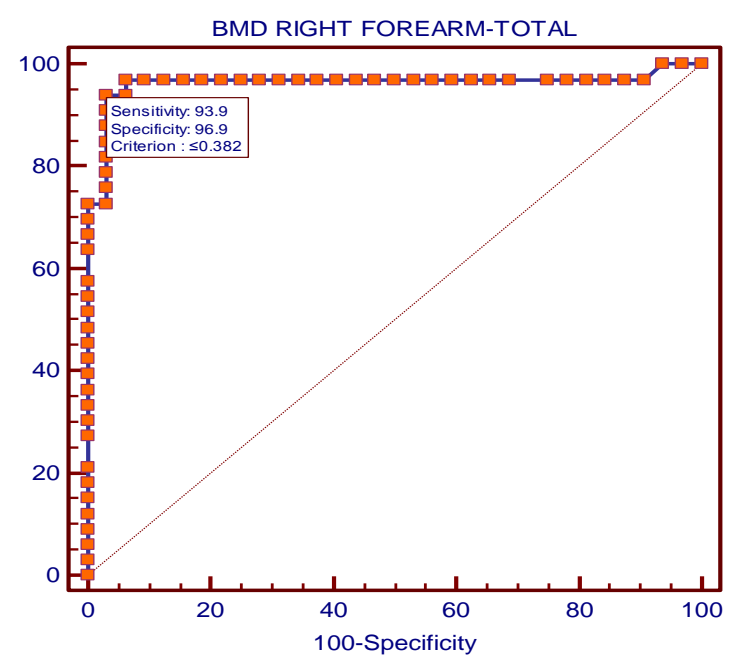

Figure 9: ROC curve of BMD of right forearm total.
For BMD right femur total hip, area under the ROC curve (AUC) was 0.857008 with standard error $=0.0519$. 95\%, confidence interval 0.747988 to 0.931474 with significance level $\mathrm{p}<0.0001$ (Area $=0.5$ ), cut off point $\leq 0.795$ having sensitivity 78.79 and specificity 90.62 (Figure 8).

For BMD right forearm total, area under the ROC curve (AUC) was 0.963542 with standard error 0.0289 . 95\%, confidence interval 0.884845 to 0.994305 with significance level $\mathrm{p}<0.0001$ (Area=0.5), cut off point $\leq 0.382$ having sensitivity 93.34 and specificity 96.87 (Figure 9).

\section{Comparison between cases and controls (Table 3)}

In our study we found that in controls (having no bony injury), the mean body weight was $63.66 \mathrm{kgs}$ with standard deviation of \pm 10.1 . While for cases (i.e. patients diagnosed with fracture), the mean body weight was $58.39 \mathrm{kgs}$ with standard deviation of \pm 8.02 . It was statistically significant ( $\mathrm{p}$ value 0.04 ). For patients having no bony injury, right forearm total, mean BMD was 0.56 $\mathrm{g} / \mathrm{cm}^{2}$ with standard deviation of \pm 0.14 . Whereas in patients with fracture, the right forearm total mean BMD was $0.31 \mathrm{~g} / \mathrm{cm}^{2}$ with standard deviation of \pm 0.1 . For patients having no bony injury, for the left forearm total mean BMD was $0.57 \mathrm{~g} / \mathrm{cm}^{2}$ with standard deviation of \pm 0.22 . When seen in patients with fracture the total mean BMD for left forearm was $0.39 \mathrm{~g} / \mathrm{cm}^{2}$ with standard deviation of \pm 0.19 . For patients having no bony injury, right femur total hip, mean BMD was $0.96 \mathrm{~g} / \mathrm{cm}^{2}$ with standard deviation of \pm 0.1 . For patients diagnosed as fracture, right femur total hip, mean BMD was 0.78 $\mathrm{g} / \mathrm{cm}^{2}$ with standard deviation of \pm 0.12 . For patients having no bony injury, for left femur total hip, mean BMD was $0.96 \mathrm{~g} / \mathrm{cm}^{2}$ with standard deviation of 0.17 . For patients diagnosed as fracture, for left femur total hip, mean BMD was $0.8 \mathrm{~g} / \mathrm{cm}^{2}$ with standard deviation of 0.12. For patients having no bony injury, spine L1-L4, mean BMD was $0.91 \mathrm{~g} / \mathrm{cm}^{2}$ with standard deviation of 0.1. For patients diagnosed as fracture, spine L1-L4, mean BMD was $0.72 \mathrm{~g} / \mathrm{cm}^{2}$ with standard deviation of 0.14 . For patients having no bony injury, spine L1, mean BMD was $0.88 \mathrm{~g} / \mathrm{cm}^{2}$ with standard deviation of 0.1 . For patients diagnosed as fracture, spine L1, mean BMD was $0.68 \mathrm{~g} / \mathrm{cm}^{2}$ with standard deviation of 0.12 . For patients having no bony injury, spine L2, mean BMD was 0.9 $\mathrm{g} / \mathrm{cm}^{2}$ with standard deviation of 0.09 . For patients diagnosed as fracture, spine L2, mean BMD was 0.7 $\mathrm{g} / \mathrm{cm}^{2}$ with standard deviation of 0.14 . For patients having no bony injury, spine L3, mean BMD was 0.9 $\mathrm{g} / \mathrm{cm}^{2}$ with standard deviation of 0.09 . For patients diagnosed as fracture, spine L3, mean BMD was 0.72 $\mathrm{g} / \mathrm{cm}^{2}$ with standard deviation of 0.16 . For patients having no bony injury, spine L4, mean BMD was 0.97 $\mathrm{g} / \mathrm{cm}^{2}$ with standard deviation of 0.14 . For patients diagnosed as fracture, spine L4, mean BMD was 0.75 $\mathrm{g} / \mathrm{cm}^{2}$ with standard deviation of 0.15 . 
Table 3: Comparison between cases and controls.

\begin{tabular}{|c|c|c|c|}
\hline & No bony injury (n=32) & Fracture $(n=33)$ & P value \\
\hline \multicolumn{3}{|l|}{ AGE } & \multirow{5}{*}{0.874} \\
\hline Mean \pm SD & $45.56 \pm 4.46$ & $45.88 \pm 5.22$ & \\
\hline Median & 45 & 45 & \\
\hline Min-Max & $41-66$ & $41-61$ & \\
\hline Inter quartile Range & $43-46.500$ & $42-48$ & \\
\hline \multicolumn{3}{|c|}{ BMD right forearm total } & \multirow{3}{*}{$<0.0005$} \\
\hline Mean \pm SD & $0.56 \pm 0.14$ & $0.31 \pm 0.1$ & \\
\hline Median & 0.51 & 0.31 & \\
\hline \multicolumn{3}{|c|}{ BMD left forearm total } & \multirow{3}{*}{$<0.0005$} \\
\hline Mean \pm SD & $0.57 \pm 0.22$ & $0.39 \pm 0.19$ & \\
\hline Median & 0.5 & 0.36 & \\
\hline \multicolumn{3}{|c|}{ BMD right femur total hip } & \\
\hline Mean \pm SD & $0.96 \pm 0.1$ & $0.78 \pm 0.12$ & \\
\hline Median & 0.99 & 0.74 & \\
\hline \multicolumn{3}{|c|}{ BMD left femur total hip } & \multirow{3}{*}{$<0.0005$} \\
\hline Mean \pm SD & $0.96 \pm 0.17$ & $0.8 \pm 0.12$ & \\
\hline Median & 1 & 0.78 & \\
\hline \multicolumn{3}{|l|}{ BMD spine L1 L4 } & \multirow{3}{*}{$<0.0005$} \\
\hline Mean \pm SD & $0.91 \pm 0.1$ & $0.72 \pm 0.14$ & \\
\hline Median & 0.95 & 0.69 & \\
\hline \multicolumn{3}{|l|}{ BMD L1 } & \\
\hline Mean \pm SD & $0.88 \pm 0.1$ & $0.68 \pm 0.12$ & \\
\hline Median & 0.89 & 0.66 & \\
\hline \multicolumn{3}{|l|}{ BMD L2 } & \\
\hline Mean \pm SD & $0.9 \pm 0.09$ & $0.7 \pm 0.14$ & \multirow{2}{*}{$<0.0005$} \\
\hline Median & 0.92 & 0.67 & \\
\hline \multicolumn{3}{|l|}{ BMD L3 } & \multirow{3}{*}{$<0.0005$} \\
\hline Mean \pm SD & $0.9 \pm 0.09$ & $0.72 \pm 0.16$ & \\
\hline Median & 0.93 & 0.68 & \\
\hline \multicolumn{3}{|l|}{ BMD L4 } & \multirow{3}{*}{$<0.0005$} \\
\hline Mean \pm SD & $0.97 \pm 0.14$ & $0.75 \pm 0.15$ & \\
\hline Median & 0.99 & 0.71 & \\
\hline
\end{tabular}

\section{DISCUSSION}

We evaluated the relationship between bone mineral density and fragility fracture. Several studies have documented the bone mineral density and fragility fracture relation in women. Usha and Krishnaswamy conducted their study on South Indian elderly women, to correlate BMD with fracture risk. They reported that BMD value of 0.72 as a fracture threshold in South Indian elderly. Increasing age and post-menopausal state negatively correlates with BMD as in other studies done in Western countries. ${ }^{13}$ According to the prospective study conducted by Earnshaw et al, Colles' fracture has been shown to be associated with an increased risk of hip fracture. In patients aged 65 years or less BMD is lower than expected at the hip. Intervention to prevent future fracture would be appropriate in women aged 65 years or less with Colles'fracture. ${ }^{14}$ Hung et al used peripheral quantitative computed tomography to measure volumetric bone mineral density in non fractured distal radius and dual-energy X-ray absorptiometry to measure areal bone mineral density at the spine and hip in patients with Colles' fractures, including 45 women who were premenopausal (age range, 40-50 years) and 39 women who were postmenopausal (age range, 51-65 years). Results suggest that low bone mineral density, at the distal radius of women who were premenopausal, was an important risk factor for low-energy Colles' fractures. ${ }^{15} \mathrm{In}$ our study low bone mineral density particular of involved site shows relation with fragility fracture which was statistically significant $(\mathrm{p}<0.0005)$. Pande et al reported low bone mineral density (BMD) is a major risk factor for fragility fractures in osteoporosis. In recent studies, its use with clinical risk factors has been shown to enhance prediction of fragility fractures. The present study was done to assess BMD in Indian patients with fragility fractures using digital X-ray radiogrammetry (DXRBMD). This study confirms lower DXR-BMD in Indian subjects with fragility fractures. This may have a potential role in fracture prediction when used with clinical risk factors in the Indian population. ${ }^{16}$ In our 
study the mean bone mineral density is low in fracture group as compared to the controls at spine, hip and wrist. It was statistically significant $(\mathrm{p}<0.0005)$.

\section{CONCLUSION}

We conclude that BMD values are a good predictor of risk for fracture in perimenopausal women and it can be used as an efficient tool to identify women at risk in perimenopausal age group. The early diagnosis hence made can significantly reduce the morbidity and mortality related to fragility fracture and off-course shortens the duration as well as cost burden of treatment. Though sample size in our study was small, an additional study with a larger sample size can further validate our findings.

\section{Funding: No funding sources}

Conflict of interest: None declared

Ethical approval: The study was approved by the institutional ethics committee

\section{REFERENCES}

1. Consensus A. Consensus development conference: diagnosis, prophylaxis, and treatment of osteoporosis. Am J Med. 1993;94(6):646-50.

2. Brown JP, Josse RG, Scientific Advisory Council of the Osteoporosis Society of Canada. 2002 clinical practice guidelines for the diagnosis and management of osteoporosis in Canada. CMAJ. 2002;167(10):1-34.

3. Kanis JA. Diagnosis of osteoporosis and assessment of fracture risk. Lancet. 2002;359(9321):1929-36.

4. Cummings SR, Nevitt MC, Browner WS, Stone K, Fox KM, Ensrud KE, Cauley J, Black D, Vogt TM. Risk factors for hip fracture in white women. N Eng J Med. 1995;332(12):767-74.

5. Van Staa TP, Leufkens HG, Abenhaim L, Zhang B, Cooper C. Use of oral corticosteroids and risk of fractures. J Bone Mineral Res. 2005;20(8):1486-93.

6. Greendale GA, Barrett-Connor E, Ingles S, Haile R. Late physical and functional effects of osteoporotic fracture in women: the Rancho Bernardo Study. J Am Geriatr Society. 1995;43(9):955-61.
7. Ferrari S, Bianchi ML, Eisman JA, Foldes AJ, Adami S, Wahl DA, et al, IOFCommittee of Scientific Advisors Working Group on Osteoporosis Pathophysiology. Osteoporosis in young adults: pathophysiology, diagnosis, and management. Osteoporosis Int. 2012;23(12):2735-48.

8. Marshall D, Johnell O, Wedel H. Meta-analysis of how well measures of bone mineral density predict occurrence of osteoporotic fractures. BMJ. 1996;312(7041):1254-9.

9. Kanis JA. Diagnosis of osteoporosis and assessment of fracture risk. Lancet. 2002;359(9321):1929-36.

10. Melton III LJ, Achenbach SJ, Gebhart JB, Babalola EO, Atkinson EJ, Bharucha AE. Influence of hysterectomy on long-term fracture risk. Fertility and sterility. 2007;88(1):156-62.

11. Torgerson DJ, Campbell MK, Thomas RE, Reid DM. Prediction of perimenopausal fractures by bone mineral density and other risk factors. J Bone Mineral Res. 1996;11(2):293-7.

12. Gupta A. Osteoporosis in India-the nutritional hypothesis. National Med J India. 1996;9:268-74.

13. Usha G, Krishnaswamy B. Bone mineral density and fracture threshold in South Indian elderly. J Association Physicians of India. 2002;50:247-9.

14. Earnshaw SA, Cawte SA, Worley A, Hosking DJ. Colles' fracture of the wrist as an indicator of underlying osteoporosis in postmenopausal women: a prospective study of bone mineral density and bone turnover rate. Osteoporosis Int. 1998;8(1):5360.

15. Hung LK, Wu HT, Leung PC, Qin L. Low BMD is a risk factor for low-energy Colles' fractures in women before and after menopause. Clin Orthop Related Res. 2005;435:219-25.

16. Babhulkar SS. Osteoporotic pertrochanteric fractures (fragility fracture). J Orthop Traumatol Rehab. 2014;7(2):108.

Cite this article as: Kumar A, Pheroz M, Chopra RK, Tungoe B, Kumar N, Aggarwal Y, et al. Evaluation of relationship between bone mineral density and fragility fracture in perimenopausal women between 40-58 years of age: a hospital based prospective observational study. Int J Res Orthop 2019;5:605-11. 